03.1;06.5;08.1

\title{
Аномальные кинетические характеристики транспорта водорода через Pd-Cu-мембраны, модифицированные пентадвойникованными цветкообразными нанокристаллитами с высокоиндексными гранями
}

\author{
(С) И.С. Петриев ${ }^{1,2}$, П.Д. Пушанкина ${ }^{1}$, И.С. Луценко ${ }^{1}$, М.Г. Барышев ${ }^{1,2}$ \\ ${ }^{1}$ Кубанский государственный университет, Краснодар, Россия \\ 2 Южный научный центр РАН, Ростов-на-Дону, Россия \\ E-mail: petriev_iliya@mail.ru \\ Поступило в Редакцию 12 апреля 2021 г. \\ В окончательной редакции 12 апреля 2021 г. \\ Принято к публикации 11 мая 2021 г.
}

\begin{abstract}
Разработана методика, позволившая впервые достичь пятикратной симметрии в палладиевых нанокристаллитах, выращенных на поверхности пленки $\mathrm{Pd}-\mathrm{Cu}$. Модификация мембраны $\mathrm{Pd}-40 \% \mathrm{Cu}$ пентадвойникованными нанокристаллитами с высокоиндексными гранями позволила достичь сверхвысокой проницаемости по водороду вплоть до $10.1 \mathrm{mmol} \cdot \mathrm{s}^{-1} \cdot \mathrm{m}^{-2}$ при $100^{\circ} \mathrm{C}$. Такая проницаемость, сопоставимая по величине с проницаемостью высокотемпературных аналогов, является аномальной, поскольку предсказанные значения должны быть более чем в 2 раза ниже полученных. Данный результат обусловливается ускорением диссоциативной адсорбции и рекомбинативной десорбции на поверхности за счет сверхвысокой активности пентадвойникованных частиц по отношению к реакциям с участием водорода, что подтверждается данными по селективности разработанных мембран.
\end{abstract}

Ключевые слова: палладийсодержащие мембраны, наноструктурированная поверхность, нанокристаллиты, пентадвойникованные частицы, водородопроницаемость.

DOI: 10.21883/PJTF.2021.16.51328.18825

Функциональные покрытия на основе благородных металлов, состоящие из нанокристаллитов различной структуры, вызывают научный интерес, обусловленный их уникальными физическими и химическими свойствами [1-3]. По мере приближения размеров кристаллитов к наноуровню отношение величины поверхности к объему пропорционально увеличивается и эффекты наноразмерной области становятся более выраженными [4]. Свойства покрытий зависят не только от размеров, но и от формы кристаллитов, варьирующейся от правильной геометрической $[5,6]$ до специфической разветвленной [7,8]. Наибольший интерес в данном случае представляют пентагонально структурированные многократно двойникованные частицы с осями симметрии пятого порядка, запрещенными законами классической кристаллографии. Как известно $[9,10]$, наночастицы палладия являются универсальным катализатором различных реакций. Включение в такие частицы высокоиндексных граней и их склонность к многократному двойникованию с образованием дефектов упаковки и границ двойных плоскостей приводят к созданию большого количества недостаточно скоординированных участков на металлической поверхности. Это обеспечивает сверхвысокую активность пентадвойникованных нанокристаллитов палладия по отношению к реакциям с участием водорода.

Такая особенность нанокристаллитов пентадвойникованной конфигурации позволяет применять их в раз- личных приложениях, из которых наиболее перспективным является мембранное. Одним из критических недостатков используемых на данный момент палладийсодержащих мембран является невысокая водородопроницаемость или полное ее отсутствие при низких температурах [11-13], что ограничивает их применение в низкотемпературных устройствах. Преодолеть это можно путем модификации поверхности мембраны высокодисперсным покрытием, которое может влиять на ускорение поверхностных (диссоциативноассоциативных) стадий и тем самым интенсифицировать транспорт водорода [14]. Поэтому основной целью настоящей работы было получение кристаллографически нетипичного пентагонально структурированного покрытия с многократно увеличенным количеством активных центров, а также оценка его влияния на газотранспортные характеристики палладий-медных мембран в низкотемпературном режиме работы (до $100^{\circ} \mathrm{C}$ ).

Нанесение двух типов наноструктурированных покрытий на обе стороны пленки $\mathrm{Pd}-40 \% \mathrm{Cu}$ осуществлялось методом электрохимического осаждения на потенциостате-гальваностате Р-40Х фирмы „Элинс“ следующими способами:

1. Классическая палладиевая чернь или „наночастицы“. Перед нанесением наноструктурированного функционального слоя пленки $\mathrm{Pd}-\mathrm{Cu}$ подвергались промывке и обезжириванию. После этого подготовленная фольга помещалась на инертном держателе в электро- 
$a$

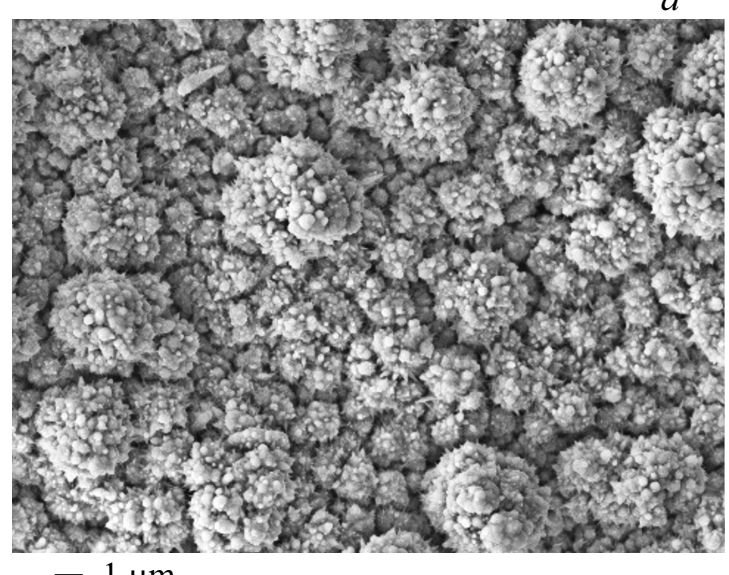

C

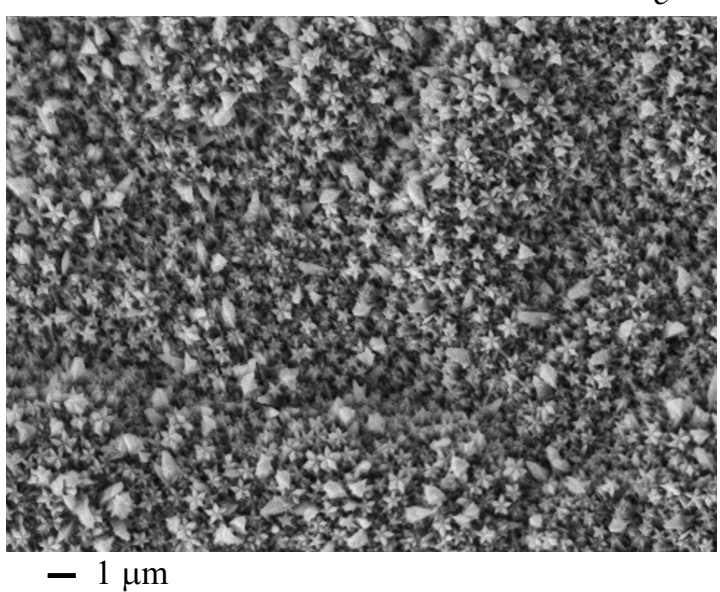

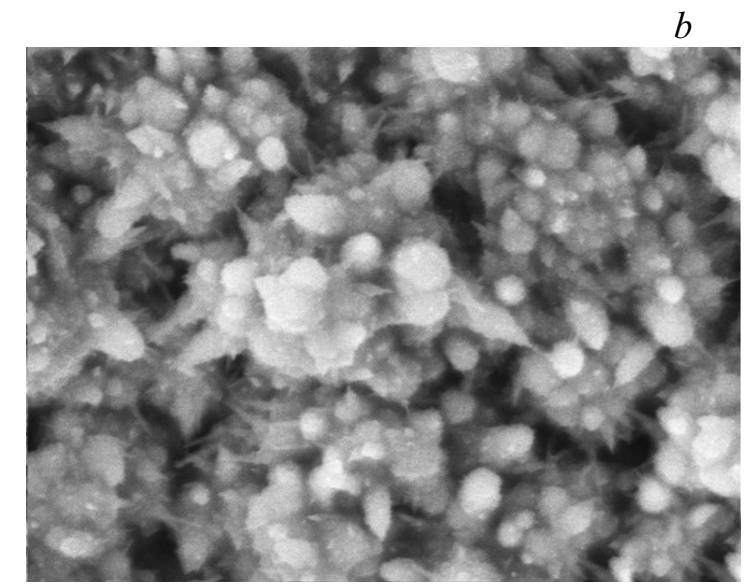

$-100 \mathrm{~nm}$

$d$

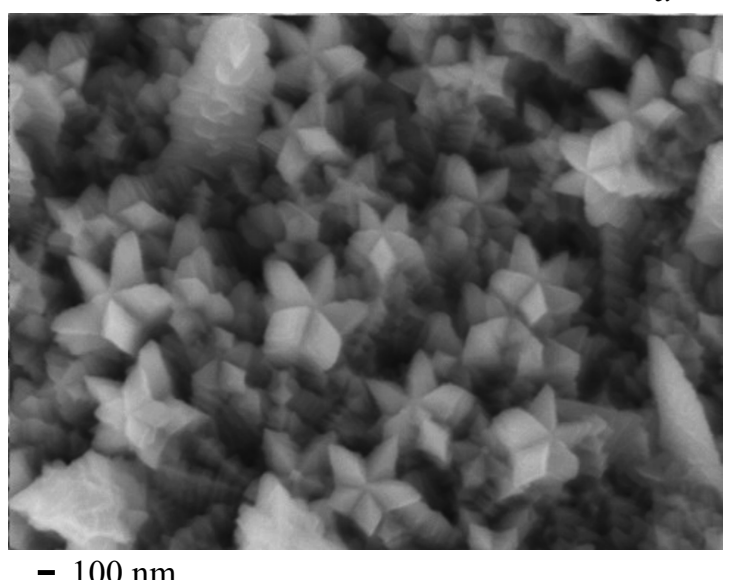

- $100 \mathrm{~nm}$

Рис. 1. Микрофотографии поверхности пленок $\mathrm{Pd}-40 \% \mathrm{Cu}$, модифицированных методами „наночастицы“ $(a, b)$ и „наноцветы“ $(c, d)$.

литическую ячейку для анодной поляризации в соляной кислоте $(0.1 \mathrm{M})$, а затем для катодной поляризации в серной кислоте $(0.05 \mathrm{M})$. Обе операции проводились при постоянной плотности тока $10-20 \mathrm{~mA} \cdot \mathrm{cm}^{-2}$. Далее ячейка заполнялась рабочим раствором хлорида палладия $\left(2 \% \mathrm{H}_{2} \mathrm{PdCl}_{4}\right)$ и проводилось осаждение высокодисперсного палладиевого покрытия при плотности тока 5-6 $\mathrm{mA} \cdot \mathrm{cm}^{-2}$, после осаждения пленка промывалась бидистиллятом.

2. Пентадвойникованные структуры или „наноцветы“. Для получения структур данного типа был изменен ряд параметров по сравнению с классическим методом: в рабочий раствор был добавлен цетилтриметиламмоний бромид, а также понижена плотность тока при осаждении до $3-4 \mathrm{~mA} \cdot \mathrm{cm}^{-2}$, что позволяло частицам выстраиваться в строго определенные формы, ранее не достигнутые при использовании других методов.

Микроскопия полученных пленок проводилась на растровом электронном микроскопе JEOL JSM-7500F. Исследование газотранспортных параметров разработанных модифицированных образцов мембран $\mathrm{Pd}-$ $40 \% \mathrm{Cu}$ осуществлялось на установке водородопроницаемости по методике, описанной в [15].
В ходе работы было изготовлено две серии образцов модифицированных мембран $\mathrm{Pd}-40 \% \mathrm{Cu}$. В первой серии пленки были модифицированы классическим методом палладиевой черни со сферическим типом частиц. Во второй серии применялся метод модификации „наноцветы“ с пентадвойникованным типом частиц. Микрофотографии поверхности двух видов разработанных образцов представлены на рис. 1.

Модифицированные образцы мембран $\mathrm{Pd}-40 \% \mathrm{Cu}$ были исследованы в процессах переноса водорода в диапазоне давлений $0.05-0.3 \mathrm{MPa}$ и температур $25-100^{\circ}$ C. По результатам эксперимента (рис. 2, a) наибольшее значение плотности потока водорода для мембран, модифицированных пентагонально структурированными нанокристаллитами, при $100^{\circ} \mathrm{C}$ составило $10.1 \mathrm{mmol} \cdot \mathrm{s}^{-1} \cdot \mathrm{m}^{-2}$. Такую проницаемость можно считать аномальной, поскольку предсказываемые значения плотности проникающего потока должны быть схожи с таковыми для мембран, модифицированных классической чернью. Несмотря на близкую шероховатость (12.1 для „наночастиц“ и 14.4 для „наноцветов“) модифицирующих покрытий, полученное значение в 2.2 раза превышает предполагаемое. Вероятно, достижение 

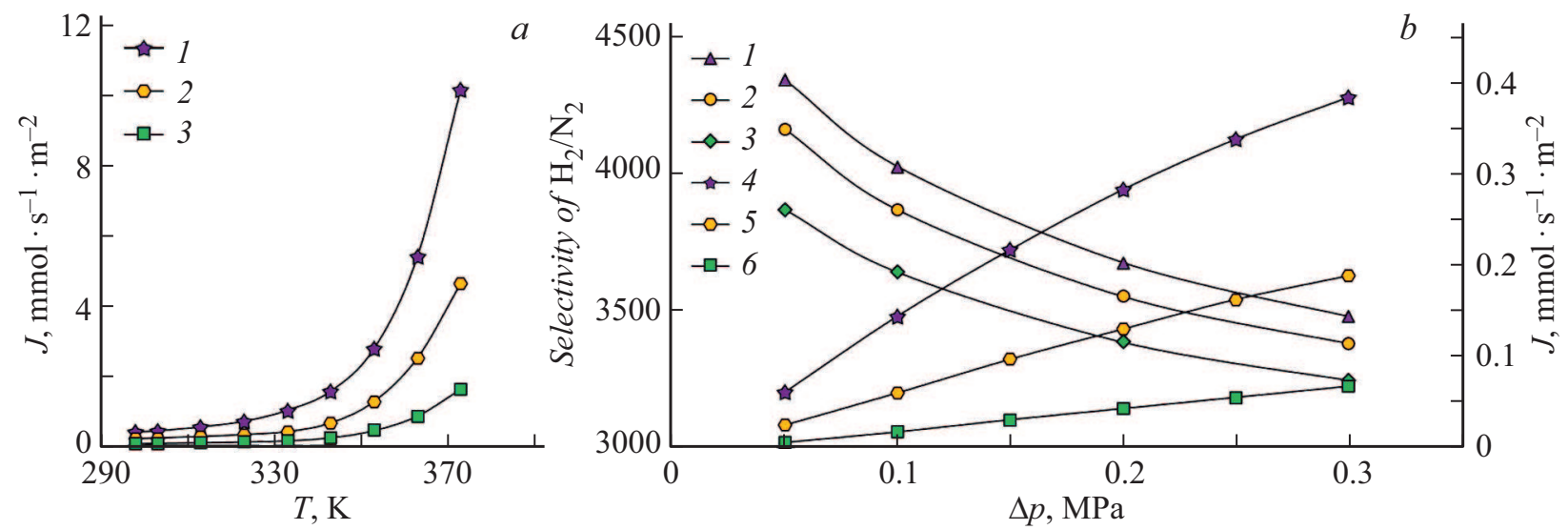

Рис. 2. $a$ - температурная зависимость плотности потока водорода при $\Delta p=0.3 \mathrm{MPa}$ через мембрану $\mathrm{Pd}-40 \% \mathrm{Cu}$, модифицированную методами „наноцветы“ $(1)$, „наночастицы“ (2), и гладкую мембрану (3). $b$ - зависимость плотности потока $(1-3)$ и селективности $\mathrm{H}_{2} / \mathrm{N}_{2}(4-6)$ при $25^{\circ} \mathrm{C}$ от избыточного давления водорода на входной стороне мембраны $\mathrm{Pd}-40 \% \mathrm{Cu}$, модифицированной методами „наноцветы“ $(1,4)$, „наночастицы“ $(2,5)$, и гладкой мембраны $(3,6)$.

подобного эффекта возможно благодаря не только увеличению шероховатости путем образования достаточно развитого поверхностного слоя, но и созданию заданной структуры нанокристаллитов. Включение высокоиндексных граней и образование дефектов упаковки и границ двойников в полученных пентадвойникованных нанокристаллитах являются ключом к созданию на их основе покрытий со сверхвысокой активностью по отношению к реакциям с участием водорода. Это сказывается на ускорении поверхностных стадий транспорта водорода и, как следствие, интенсификации проникающего потока через разрабатываемые низкотемпературные мембраны, при этом демонстрируются показатели проникновения водорода, сопоставимые с таковыми для высокотемпературных аналогов.

Селективность испытываемых мембран, модифицированных методами „наночастицы“ и „наноцветы“, определялась по соотношению проникающих потоков $\mathrm{H}_{2}$ и $\mathrm{N}_{2}$. Согласно полученным данным (рис. 2, $b$ ), наибольшее значение проницаемости $\mathrm{H}_{2} / \mathrm{N}_{2}$ наблюдалось для мембран с пентагонально структурированным покрытием 3479 при $0.3 \mathrm{MPa}$. Данные по селективности подтверждают отсутствие ошибки эксперимента и удостоверяют, что аномально высокая проницаемость обосновывается транскристаллическим переносом водорода, а не наличием дефектов в мембране (уплотнений, микроотверстий и др.).

Таким образом, в работе впервые достигнута пятикратная симметрия в палладиевых нанокристаллитах, синтезированных на палладий-медной пленке. Модификация мембраны $\mathrm{Pd}-40 \% \mathrm{Cu}$ такими пентадвойникованными частицами позволила достичь аномально высокой проницаемости по водороду вплоть до $10.1 \mathrm{mmol} \cdot \mathrm{s}^{-1} \cdot \mathrm{m}^{-2}$. Это стало возможным благодаря созданию на поверхности мембран нанокристаллитов неклассической структуры, обладающих сверхвысокой активностью по отношению к реакциям с участием водорода.

\section{Финансирование работы}

Работа выполнена при финансовой поддержке Российского фонда фундаментальных исследований и администрации Краснодарского края в рамках научного проекта № 20-42-235001, государственного задания Кубанского государственного университета № FZEN-20200022 и Кубанского научного фонда в рамках гранта № НИП-20.1/13.

\section{Конфликт интересов}

Авторы заявляют, что у них нет конфликта интересов.

\section{Список литературы}

[1] Г.Ф. Копытов, В.В. Малышко, А.А. Елкина, А.В. Моисеев, С.С. Джимак, А.А. Басов, М.Г. Барышев, Изв. вузов. Физика, 63 (6), 82 (2020). DOI: 10.17223/00213411/63/6/82 [Пер. версия: 10.1007/s11182-020-02128-x].

[2] E.Y. Mironova, A.A. Lytkina, M.M. Ermilova, N.V. Orekhova, N.A. Zhilyaeva, N.R. Roshan, V.M. Ievlev, A.B. Yaroslavtsev, Pet. Chem., 60 (11), 1232 (2020). DOI: $10.1134 / \mathrm{S} 0965544120110158$

[3] И.С. Петриев, М.Г. Барышев, К.А. Воронин, И.С. Луценко, П.Д. Пушанкина, Г.Ф. Копытов, Изв. вузов. Физика, 63 (3), 97 (2020). DOI: 10.17223/00213411/63/3/97 [Пер. версия: 10.1007/s11182-020-02056-w].

[4] Z.-Y. Zhou, N. Tian, J.-T. Li, I. Broadwell, S.-G. Sun, Chem. Soc. Rev., 40 (7), 4167 (2011). DOI: 10.1039/c0cs00176g

[5] Q. Li, M. Shao, S. Zhang, X. Liu, G. Li, K. Jiang, Y. Qian, J. Cryst. Growth, 243 (2), 327 (2002). DOI: $10.1016 / \mathrm{S} 0022-0248(02) 01531-2$

[6] B. Zhu, H. Guesmi, J. Creuze, B. Legrand, C. Mottet, Phys. Chem. Chem. Phys., 17 (42), 28129 (2015). DOI: $10.1039 / \mathrm{C} 5 \mathrm{CP} 00491 \mathrm{H}$ 
[7] R.G. Weiner, C.J. DeSantis, M.B.T. Cardoso, S.E. Skrabalak, ACS Nano, 8 (8), 8625 (2014). DOI: 10.1021/nn5034345

[8] E. Ye, M.D. Regulacio, S.-Y. Zhang, X.J. Loh, M.-Y. Han, Chem. Soc. Rev., 44 (17), 6001 (2015). DOI: $10.1039 / C 5 C S 00213 C$

[9] I. Petriev, P. Pushankina, I. Lutsenko, N. Shostak, M. Baryshev, Nanomaterials, 10 (10), 2081 (2020). DOI: 10.3390/nano10102081

[10] M.E. King, M.L.Personick, Nanoscale, 9 (45), 17914 (2017). DOI: $10.1039 / \mathrm{c} 7 \mathrm{nr} 06969 \mathrm{c}$

[11] C. Zhao, B. Sun, J. Jiang, W. Xu, Int. J. Hydrogen Energy, 45 (35), 17540 (2020). DOI: 10.1016/j.ijhydene.2020.04.250

[12] В.Н. Алимов, А.О. Буснюк, М.Е. Ноткин, А.И. Лившиц, Письма в ЖТФ, 40 (5), 88 (2014). [Пер. версия: 10.1134/S1063785014030031].

[13] C.H. Lee, Y.S. Jo, Y. Park, H. Jeong, Y. Kim, H. Sohn, C.W. Yoon, S.W. Nam, H.C. Ham, J. Han, J. Membr. Sci., 595, 117506 (2020). DOI: 10.1016/j.memsci.2019.117506

[14] И.С. Петриев, С.Н. Болотин, В.Ю. Фролов, М.Г. Барышев, ДАН, 486 (2), 163 (2019).

DOI: $10.31857 / \mathrm{S} 0869-56524862163-167$

[Пер. версия: 10.1134/S1028335819050057].

[15] I. Petriev, P. Pushankina, S. Bolotin, I. Lutsenko, E. Kukueva, M. Baryshev, J. Membr. Sci., 620, 118894 (2021).

DOI: 10.1016/j.memsci.2020.118894 